\title{
Sun Drying of Sugarcane Press Mud as a Future Feed for Livestock
}

\author{
S. Sahu ${ }^{1}$, B.H.M. Patel ${ }^{2}$, Archana Sarangi ${ }^{3 *}$, Amit ${ }^{1}$ and D. Upadhyay ${ }^{4}$ \\ ${ }^{1}$ Department of LPM, LUVAS, Hisar, Haryana, India \\ ${ }^{2}$ LPM Section, IVRI Campus, Bangalore, Karnataka, India \\ ${ }^{3}$ Division of Animal Physiology, NDRI, Karnal, Haryana, India \\ ${ }^{4}$ Department of LPM, IVRI Campus, Mukteshwar, Uttarakhand, India
}

*Corresponding author

\section{A B S T R A C T}

\begin{tabular}{|l|}
\hline K e y w o r d s \\
Drying, Sugar cane \\
Press mud, \\
Livestock, Feed \\
\hline Article Info \\
\hline $\begin{array}{l}\text { Accepted: } \\
\text { 20 March } 2018 \\
\text { Available Online: } \\
\text { 10 April } 2018\end{array}$ \\
\hline
\end{tabular}

Fresh sugarcane press mud (SPM), an agricultural waste was collected from the sugar mill near Bareilly city for drying for its long term storage as a future feed in the livestock ration. Drying experiment was done by spreading 1" (T1) and 2" (T2) thickness under the sun and 2 times (M2) and 4 times (M4) mulching were performed under each thickness. Under sun drying, significant $(\mathrm{P}<0.05)$ difference was recorded between two times and four times mulching under a particular thickness group for various labour cost (man min.) parameters. Overall mean of labour attributes were significantly higher in T2 than T1 under sun drying. From the experiment it was clear that the thickness had profound effect drying under sun drying. While different mulching under each thickness were not differed greatly except few parameters. It can be concluded that lower thickness ( 1 ") with less time mulching (2 times/day) can effectively dry the SPM in a short time with less labour requirement.

\section{Introduction}

Sugarcane Press Mud (SPM) is one of the byproduct obtained from commercial sugarcane factory. Out of 30 million tonnes of SPM produced per annum across the globe, India produces around 3.6 million tons (FAO, 2011). Generally SPM is used as organic manure for enrichment of soil (Bhosale et al., 2012; Jamil et al., 2008 and Rangaraj et al., 2007). Besides, wax extracted from SPM has several applications in various industries (Bhosale et al., 2012). Further, recent studies have made its inclusion in the diets of sheep (Suresh et al., 2006), goat (Ankita et al.,
2015), pig (Sahu et al., 2014), broiler (Budeppa et al., 2009 and Suresh et al., 2012) and layer (Suma et al., 2007) in different percentage in the concentrate mixture which proves it as an alternative feed ingredient in the livestock ration. Further, the fresh SPM obtained from sugarcane industry contains high moisture (Sahu et al., 2016; Bhosale et al., 2012; Suma et al., 2007) and it is difficult to store. Therefore its drying is utmost important for its long term storage for incorporation in the ration of livestock. Since there is no work has been done on drying of SPM earlier, an attempt has been made to dry the SPM in field condition for its future use. 


\section{Materials and Methods}

Fresh sample of SPM was procured from sugarcane factory (JK Sugar meal), Bareilly to IVRI, Izzatnagar. For drying experiment, fresh SPM was spread on the dry floor making a unit (bed) measuring $1 \times 1 \mathrm{~m}^{2}$. In order to study time taken for drying based on the physical properties [(colour, odour, consistency and fungal growth), dry matter (\%) change and labour (man min.)], sun drying was carried out. Approximately 9 quintals of fresh SPM was allowed to dry under sun. Further, two thickness, 2" (T1) and 1" (T2) beds of 6 units each were maintained under sun drying and the approximate quantity of fresh SPM under T1 remained was 6 quintals and under T2 was 3 quintals. So the fresh SPM for each bed $(1 \times 1$ $\mathrm{m}^{2}$ ) under $2^{\prime \prime}$ thickness was nearly 1 quintal and under $1 "$ thickness was nearly 0.5 quintal. For quick drying under each thickness 2 times mulching (M2) (8 AM and 5 PM) and 4 times mulching (M4) (8 AM, $11 \mathrm{AM}, 2 \mathrm{PM}$ and 5 PM) were done. In each time mulching for a unit bed, the labour in man min. required was recorded by the same person with the help of a stop watch all throughout the experimental period till the DM \% achieved $90 \pm 2 \%$.

Temperature and relative humidity under sun were also recorded daily as a source of indication of microclimate. Maximum, minimum and mean temperature as well as relative humidity during each day of experiment was recorded. Microclimatic indicators were recorded four times daily i.e. morning $(10 \mathrm{am})$, afternoon $(2 \mathrm{pm})$, evening $(5 \mathrm{pm})$ and night $(10 \mathrm{pm})$ to provide better picture of diurnal conditions. The average maximum \& minimum temperature in the experimental period recorded under sunlight was $38.71^{\circ} \mathrm{C}$ and $16.07^{\circ} \mathrm{C}$ and average Relative humidity (RH\%) was $55 \%$. On each day physical parameters viz. colour (On visualization with naked eye), odour (smelling by standing close to the bed), consistency
(Handful of sample taken and light squeezing and subsequently slow releasing), fungal (presence or absence of white/orange growth on the surface) growth were observed with naked eyes. Each day a ranking was made for various units by taking a 1 to 5 point scale (Table 1) for each parameter under study. Further, daily dry matter percentage (DM\%) of each unit (bed) under two treatments was estimated by taking a representative sample and kept inside the hot air oven maintained at $100 \pm 1 \mathrm{oC}$ for $12 \mathrm{~h}$. The same parameters were recorded for each unit daily till it achieved a Dry matter (DM) percentage of $90 \pm 2 \%$.

Data generated was analysed using statistical package for the social sciences (SPSS, Chicago, USA) using independent T-test. Treatment means are presented along with standard errors of the mean (SEM) where ' $t$ ' value was computed and for others only mean value are given in the table 2 .

\section{Results and Discussion}

Drying experiment for SPM revealed that there was no variation among the units under each mulching and between mulching (M2 and M4) for both the thickness (T1 and T2) for various parameters except the mean days taken to achieve the 90\% DM, in sun drying case. It was observed that under sun drying (Table 2), M2 group under 1" thickness (T1M2) achieved the same mean days as like M4 group (T1M4) for parameters viz. odour (5.00) and fungal growth (3.00), but took an extra mean day for colour and consistency (5.00 mean days for 2 times and 4.00 mean days for 4 times mulching) to achieve the desirable traits. To achieve 90\% DM, 4.00 mean days were taken by the T1M2 group while T1M4 took mean days of 3.33 . Significant difference $(\mathrm{p}<0.05)$ of mean days to achieve $90 \%$ DM was observed between T1 (3.67 \pm 0.211$)$ and $\mathrm{T} 2(5.17 \pm 0.167)$, besides colour and consistency (Table 2) parameters. 
The ' $t$ ' values could not be computed for rest parameters, viz. odour and fungal growth because of uniformity in the data, but clearly indicated that $\mathrm{T} 1$ took less mean days (5.00 for odour and 3.00 for fungal growth) than T2 (7.00 for odour and 4.00 for fungal growth). Significant $(\mathrm{P}<0.05)$ difference was recorded between two times and four times mulching under a particular thickness group for various labour cost (man min.) parameters. Total man min. required to dry $\mathrm{T} 1 \mathrm{M} 2$ was $44.00 \pm 2.31$ which was significantly lower than T1M4 which took $75.33 \pm 12.45$ man min. Similarly man min./day and man min./q to dry were $11.00 \pm 0.57, \quad 88.00 \pm 4.61$ for $\mathrm{T} 1 \mathrm{M} 2$ and $22.33 \pm 1.45,150.67 \pm 18.02$ for $\mathrm{T} 1 \mathrm{M} 4$ group, respectively and the corresponding value were significantly lower $(\mathrm{P}<0.05)$ in $\mathrm{T} 1 \mathrm{M} 2$ as compared to T1M4. When overall mean between two thickness were compared, significantly higher $(\mathrm{P}<0.05)$ labour cost (man min.) was involved in 2" thickness as compared to 1" thickness group for all the labour parameters. Total man min. for T1 and T2 were 59.67 \pm 9.01 and $245.33 \pm 32.32$ respectively, while the other parameters viz. Man min./day and man min./q dry were $16.66 \pm 2.63, \quad 119.44 \pm 44.14$ for $\mathrm{T} 1$ and $48.00 \pm 6.89,245.33 \pm 32.32$ for T2 respectively. All values were significantly higher in $\mathrm{T} 2$ than T1 under sun drying. Patoo et al., (2011) reported that for drying concentrate jaggery scum (CJS) feed blocks of various shapes under sun shine required 5 to 8 days. Similarly, both T2M2 and T2M4 group revealed no difference in the mean days to achieve desirable parameters (Table 2) except for the time to achieve $90 \%$ DM, where 5.33 and 5.00 mean days were taken by 2 times mulching and 4 times mulching group, respectively. The present findings corroborated with the results of Salem and Nefzaoui (2003) who reported that feed blocks must be turned time to time to accelerate drying process. The present findings were not in agreement with Patel et al., (2009) who reported that colour, odour and consistency were not changed upto a week during the month of March when jaggery filter cake was kept inside the drum.

Table.1 Physical score (1-5 pt. scale) to parameters/traits under sun drying experiment

\begin{tabular}{|l|l|l|l|l|}
\hline Score & colour & odour & Consistency & fungal growth \\
\hline $\mathbf{1}$ & Dark brown & Sweetish & $\begin{array}{l}\text { Retains Shape with finger } \\
\text { imprints }\end{array}$ & Fresh sample with no growth \\
\hline $\mathbf{2}$ & $\begin{array}{l}\text { Medium } \\
\text { brown }\end{array}$ & $\begin{array}{l}\text { Light } \\
\text { sweetish }\end{array}$ & $\begin{array}{l}\text { Retains Shape without finger } \\
\text { imprints }\end{array}$ & $\begin{array}{l}\text { Growth covering more than } \\
60 \%\end{array}$ \\
\hline $\mathbf{3}$ & fermenting & $\begin{array}{l}\text { Does not retain shapes but } \\
\text { breaks in to larger flakes }\end{array}$ & $\begin{array}{l}\text { Growth covering more than } \\
30-60 \%\end{array}$ \\
\hline $\mathbf{4}$ & Light brown & $\begin{array}{l}\text { Light } \\
\text { fermenting }\end{array}$ & $\begin{array}{l}\text { Does not retain shapes but } \\
\text { breaks in to smaller flakes }\end{array}$ & $\begin{array}{l}\text { Growth covering less than } \\
10-30 \%\end{array}$ \\
\hline $\mathbf{5}$ & $\begin{array}{l}\text { Very light } \\
\text { brown }\end{array}$ & No smell & Not at all flakes formation & $\begin{array}{l}\text { Dry sample with no growth } \\
(<10 \%)\end{array}$ \\
\hline
\end{tabular}


Table.2 Mean days taken to achieve desirable drying traits and labour cost (man minute) involved under sun drying condition

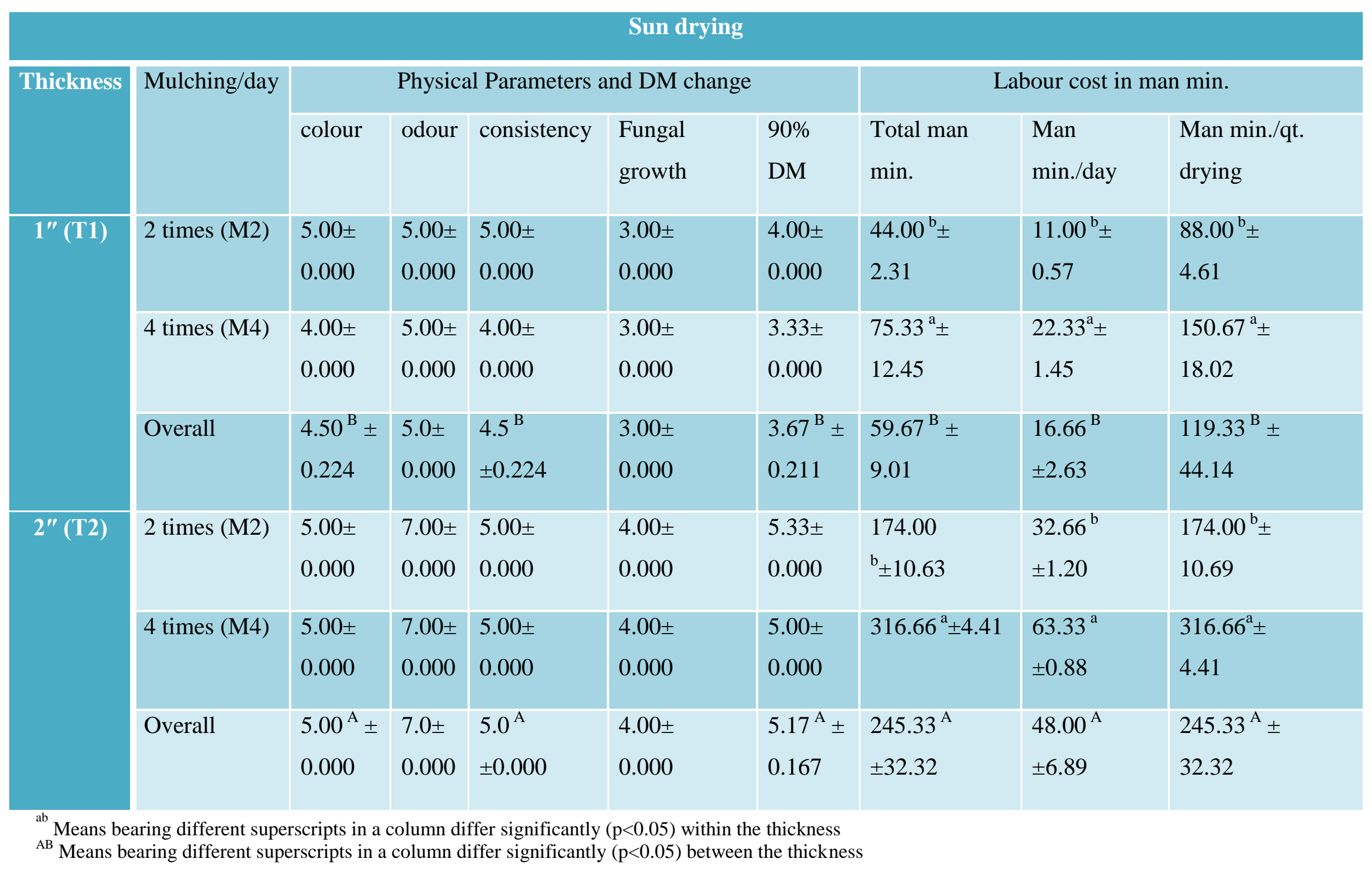


From the experiment it was clear that the thickness had profound effect under sun drying. While different mulching under each thickness were not differed greatly except few parameters. It can be concluded that lower thickness (1") with less time mulching (2 times/day) can effectively dry the SPM in a short time with less labour requirement.

\section{References}

Ankita, Saha, S.K., Malapure, C.D. and Sahu, S. 2015. Effect of feeding sugarcane press mud (SPM) on dry matter intake, FCR and average daily gain in goat kids. Indian Veterinary Journal, 92 (7): 90-91.

Anon (1994). Instruction Manual. Ballistic Bomb Calorimeter. Sanyo Gallenkamp PLC, park House, Leicester LE3 2UZ.

Bhosale, P.R., Chonde, S.G., Nakade, D.B. and Raut, P.D. 2012. Studies on PhysicoChemical Characteristics of Waxed and Dewaxed Pressmud and its effect on Water Holding Capacity of Soil. ISCA J. Biological Sci. 1: 35-41.

Budeppa, H.B., Reddy, B.S.V. and Suresh, B.N. 2009. Screening sugarcane press mud as a source of minerals. Indian Vet. J. 86: 323.

FAO, 2011. FAOSTAT. Food and Agriculture Organization of the United Nations.

Jamil, M., Qasim, M. and Sharif-Zia, M. 2008. Utilization of pressmud as organic amendment to improve physico-chemical characteristics of calcareous soil under two legume crops. J. Chem. Soc. Pak., 30(34): 577-583.

Patel, M., Sharma, R.J., Kumar, A., Tiwari, D.P., Kumar, S., and Panja, A. 2009. Composition of jaggery filter cake and its acceptability in pig feeding. Indian vet. J., 86: 1282-1283.

Patoo, R.A., Kumar, S. and Patel, M. 2011. Formulation of concentrate jaggery scum feed blocks for pigs. Indian Vet. J., 88(8):148-149.

Rangaraj, T., Somasundaram, E.M., Amanullah, M., Thirumurugan, V., Ramesh, S. and Ravi, S. 2007. Effect of agro-industrial wastes on soil properties and yield of irrigated finger miller (Eleusine coracana L. Gaertn) in coastal soil. Res. J. Agric. \& Biolog. Sci. 3: 153-156.

Sahu, S., Patel, B.H.M., Malapure, C.D., Ankita, Singh, M., Verma, A.K., Singh, G. and Bhusan, B. (2016). Screening of sugarcane press mud as a potential alternative feed for livestock. Indian Journal Animal Research, 50 (2): 207210.

Sahu, S., Patel, B.H.M., Dutt, T. and Verma, A.K. 2014. Effect of graded level of sugarcane pressmud in ration on carcass characteristics of crossbred (Landrace $x$ Desi) pigs. Indian Journal of Animal Sciences, 84 (10): 1109-1112.

Salem, H. Ben and Nefzaoui, A. 2003. Feed blocks as alternative supplements for sheep and goats: A review. Small Ruminat Res., 49: 275-288.

Suma, N., Reddy, B.S.V., Gloridoss, R.G., Rao, R., Singh, K.C., Rekha, M.T. and Gomes, A.R. (2007). Egg quality traits of layers influenced by supplementation of different levels of sugarcane press residue. Inter. J. Poult. Sci. 6: 102-106

Suresh, B.N., Reddy, B.S.V., Prabhu, T.M. and Gowda, N.K.S. 2012. Growth performance of broilers fed Sugarcane Press Residue incorporated diets. Anim. Nutr. Feed Technol. 12: 219-227.

Suresh, B.N., Reddy, B.S.V., Prabhu, T.M., Gloridoss, R.G. and Jagadish, B. 2006. Nutritional evaluation of sugarcane pressmud in lambs. Indian J. Anim. Nutr. 23: 47-49.

\section{How to cite this article:}

Sahu, S., B.H.M. Patel, Archana Sarangi, Amit and Upadhyay, D. 2018. Sun Drying of Sugarcane Press Mud as a Future Feed for Livestock. Int.J.Curr.Microbiol.App.Sci. 7(04): 2530-2534. doi: https://doi.org/10.20546/ijcmas.2018.704.289 